Review Article

\title{
Prevalence of Erectile Dysfunction in Patients with Diabetes Mellitus and Its Association with Body Mass Index and Glycated Hemoglobin in Africa: A Systematic Review and Meta-Analysis
}

\author{
Wondimeneh Shibabaw Shiferaw (D), ${ }^{1}$ Tadesse Yirga Akalu, ${ }^{2}$ and Yared Asmare Aynalem (iD ${ }^{1}$ \\ ${ }^{1}$ Lecturer of Nursing, Department of Nursing, College of Health Science, Debre Berhan University, Debre Berhan, Ethiopia \\ ${ }^{2}$ Lecturer of Nursing, Department of Nursing, College of Health Science, Debre Markos University, Debre Markos, Ethiopia \\ Correspondence should be addressed to Wondimeneh Shibabaw Shiferaw; wshibabaw21@gmail.com
}

Received 12 November 2019; Revised 16 December 2019; Accepted 30 December 2019; Published 18 January 2020

Academic Editor: A. Lania

Copyright (c) 2020 Wondimeneh Shibabaw Shiferaw et al. This is an open access article distributed under the Creative Commons Attribution License, which permits unrestricted use, distribution, and reproduction in any medium, provided the original work is properly cited.

\begin{abstract}
Background. Mortality and morbidity in patients with diabetes mellitus (DM) are attributed to both microvascular and macrovascular complications. However, there is a significant amount of variation in the primary studies on DM regarding the prevalence of erectile dysfunction (ED) in Africa. Therefore, this study was aimed to estimate the pooled prevalence of ED patients with DM and its association with body mass index (BMI) and glycated hemoglobin in Africa. Methods. PubMed, Web of Science, Cochrane Library, Scopus, PsycINFO, African Journals Online, and Google Scholar were searched for studies that looked at ED in DM patients. A funnel plot and Egger's regression test were used to determine publication bias. The $I^{2}$ statistic was used to check heterogeneity between the studies. DerSimonian and Laird random-effects model was applied to estimate the pooled effect size. The subgroup and meta-regression analyses were conducted by country, sample size, and year of publication. Sensitivity analysis was deployed to see the effect of a single study on the overall estimation. STATA version 14 statistical software was used for the meta-analysis. Result. A total of 13 studies with 3,501 study participants were included in this study. We estimated that the pooled prevalence of ED in patients with DM in Africa was 71.45\% (95\% CI: 60.22-82.69). Diabetic patients whose BMI was $\geq 30 \mathrm{~kg} / \mathrm{m}^{2}$ were 1.26 times more likely to develop $\mathrm{ED}(\mathrm{AOR}=1.26$; $95 \% \mathrm{CI}: 0.73-2.16)$ and whose glycated hemoglobin was $<7 \%$ were $7 \%$ less likely to develop ED (AOR=0.93; 95\% CI: 0.5-5.9), although they were not significantly associated with ED. Conclusions. The prevalence of ED in DM patients in Africa remains high. Therefore, situation-based interventions and country context-specific preventive strategies should be developed to reduce the prevalence of ED among patients with DM.
\end{abstract}

\section{Introduction}

Diabetes is a major public health problem, increasingly affecting millions of people across the globe [1]. Approximately 425 million people suffered from diabetes mellitus (DM) globally in 2017; by 2045, this is projected to rise to 629 million [2]. The prevalence of DM in Africa also continues to rise, thus imposing an extraburden on Africa's healthcare systems [3]. Mortality and morbidity in patients with DM are often the result of both micro- and macrovascular complications. One common and yet underestimated complication of DM is erectile dysfunction (ED) [4]. Indeed, it is estimated that the global prevalence of ED should reach 322 million by 2025 [5].
ED is the inability to achieve and maintain an erection sufficient to permit satisfactory sexual intercourse [6]. It may result from psychological, neurologic, hormonal, or arterial impairment or from a combination of these factors [7].

The pathophysiology of ED in DM is related to multiple mechanisms, including endothelial dysfunction, the accumulation of advanced glycation end products, oxidative stress, and autonomic neuropathy $[4,8]$. For instance, diabetes may affect the cavernous nerve terminals and endothelial cells, resulting in a deficiency in neurotransmitters [9].

Large differences have been reported on the prevalence of ED in patients with DM in different studies. For instance, ED has been reported in $49 \%$ of the male population in 
England [10], 35.8\% in Italy [11], 65.4\% in Korean [12], 86.1 in Saudi Arabia [13], 31\% in Kuwait [14], 38.9\% in India [15], $77.1 \%$ in South Africa [16], and 67.9\% in Ghana [17]. The risk factors for ED are multifactorial and complex. Studies suggest that risk factors for ED in patients with DM include hypertension $[14,16,18,19]$, heart disease [18], cigarette smoking [14, 16, 18-20], low education level [14], increasing body mass index (BMI) $[14,15,17]$, poor glycemic control $[14,17,21]$, age above or equal to 50 years $[14,15,17,20,22]$, metabolic syndrome [23], testosterone deficiency [24], increasing duration of diabetes [22], presence of depressive symptoms [15], high income [17], fat-rich diets [25], and other diabetic complications [26].

Patients with ED often suffer from poor quality of life $[19,27]$, anxiety when sexual ability declines [28], mutual mistrust, general unhappiness, and fear of losing support from their partner [29]. However, effectively controlling the disease can reduce some of these negative effects. For instance, several studies have shown that about one-third of men with ED show improvement in sexual function based on lifestyle interventions, such as diet, exercise and weight loss, cessation of smoking, counseling, and appropriate glycemic control through diet [30, 31]. Different primary studies in Africa show the magnitude of ED as a health issue in the region. However, variation was observed among these studies. Therefore, this systematic review and meta-analysis aimed to estimate the pooled prevalence of ED in patients with DM and its association with BMI and glycated hemoglobin in Africa.

\section{Methods}

2.1. Data Sources and Literature Search Strategy. Electronic databases, such as PubMed, Google Scholar, African Journals Online, Scopus, Web of Science, PsycINFO, and the Cochrane library, were independently and systematically searched by the authors. In addition, a manual search of gray literature and other related articles were deployed to identify additional relevant research. Data from the International Diabetic Federation (IDF) were also searched and used. This search involved articles published from January 1, 1990, to September 4, 2019. The searches were restricted to full texts, free articles, human studies, and English-language publications. Authors were contacted for full texts of their articles through e-mail, if necessary. The search was conducted using the following terms and phrases: "erectile dysfunction," "sexual dysfunction," "impotence," "diabetes mellitus," and "Africa." Boolean operators like "AND" and "OR" were used to combine search terms. Particularly, to fit the advanced PubMed database, the following search strategy was used ("erectile dysfunction" OR "impotence" OR "sexual dysfunction") AND ("diabetes mellitus") AND (“Africa”).

\subsection{PECOS Guide}

2.2.1. Type of Participants. This review considered studies that included adult male patients aged 18 years or older who had been diagnosed with DM.
2.2.2. Type of Exposure. In this meta-analysis, patients with DM whose BMI was $\geq 30 \mathrm{~kg} / \mathrm{m}^{2}$ and glycated hemoglobin was $>7 \%$ were considered as exposed variable to estimate its effect on ED.

2.2.3. Comparison. In this meta-analysis, patients with DM whose BMI was $18.5-24.9 \mathrm{~kg} / \mathrm{m}^{2}$ and glycated hemoglobin was $<7 \%$ were considered as control variable for ED.

2.2.4. Study Outcome. The outcome of this study was the prevalence of ED among men with DM.

2.3. Types of Study Designs Used in This Review. This systematic review included observational studies such as retrospective or prospective cohort studies, and cross-sectional and case-control studies, where ED among DM patients has been reported.

2.4. Eligibility Criteria. Studies were included in the metaanalysis if they adhered to the following guidelines: (1) all observational studies needed to report the prevalence of ED; (2) articles must be published in peer-reviewed journals or gray literature; (3) articles must be published in English between 1990 and 2019; and (4) studies must examine an African population and include male participants. Studies were excluded if (1) they were not fully accessible; (2) studies with duplicated citation; (3) they possessed a poor quality score as per the stated criteria; (4) they failed to determine the desired outcome (i.e., ED); or (5) they included only females.

2.5. Selection and Quality Assessment. Two independent investigators screened the title and abstract of all of the potential studies to be included in our analysis. Data were extracted from each of these studies using the standardized data extraction format prepared in a Microsoft Excel worksheet by the three authors independently. For each article, we extracted data regarding the names of the authors, year of publication, study area, study design, sample size, data collection year, sampling technique, diagnostic criteria used for ED, reported prevalence with its 95\% confidence interval (CI), and information regarding the associated factors. When some information was missing, first or corresponding authors of the article were contacted at least twice in a month to obtain the variables of interest. The quality of each included study was assessed using the Newcastle-Ottawa scale (NOS) [32]. This scale has several key criteria including the representativeness of the sample, response rate, measurement tool used, comparability of the subject, and the appropriateness of the statistical test used to analyze the data. Studies were included in the analysis if they scored $\geq 5$ out of 10 points in three domains of ten modified NOS components for a cross-sectional study [33]. Any disagreements at the time of data abstraction were resolved by discussion and consensus (Supplementary file 1). 
2.6. Statistical Analysis. To obtain the pooled effect size, a meta-analysis using the random-effects DerSimonian and Laird model was performed [34, 35]. Heterogeneity across the included studies was checked using the chi-square-based Q test and the $I^{2}$ statistical test with a value of $\geq 75 \%$ for the first test and $p<0.05$ indicating the presence of significant heterogeneity [35]. To investigate the sources of heterogeneity, meta-regression and subgroup analyses were performed. Potential publication bias was assessed by visual inspection of a funnel plot. In addition, an Egger regression test was conducted, and $p \leq 0.05$ was considered statistically significant for the presence of publication bias [36]. Sensitivity analysis was deployed to see the effect of a single study on the overall effect estimation. The meta-analysis was performed using the STATA version 14 statistical software for Windows [37].

2.7. Data Synthesis and Reporting. To estimate the overall prevalence of ED in patients with DM, the Preferred Reporting Items for Systematic Reviews and Meta-Analyses (PRISMA) guideline was used [38]. The entire process of study screening, selection, and inclusion were described with the aid of a flow diagram. Results were presented using forest plots and summary tables.

\section{Results}

3.1. Search Results. In the first step of our search, 1,622 studies were retrieved. About 1,617 studies were found from seven international databases, and the remaining 5 were through a manual search. The databases included PubMed (43), Scopus (28), Google Scholar (800), Web of Science (317), Cochrane Library (3), PsycINFO (19), and African Journals Online (407). Of these, 879 duplicate records were identified and removed. From the remaining 743 articles, 677 articles were excluded after reading the titles and abstracts based on the predefined eligibility criteria. Finally, 66 full-text articles were assessed for their eligibility. Based on the predefined criteria and quality assessment, only 13 articles were included for the final analysis (Figure 1).

3.2. Baseline Characteristics of the Included Studies. In the current meta-analysis, a total of 13 studies with 3,501 study participants were included to estimate the pooled prevalence of ED among DM patients. With respect to study design, the majority (95\%) of the studies included were cross sectional. The studies varied substantially in sample size, ranging from 70 to 599 . The highest prevalence (95\%) of ED was reported in a study conducted in South Africa [39], whereas the lowest prevalence $(36 \%)$ was reported in a study also conducted in South Africa [40]. Overall information regarding the prevalence of $\mathrm{ED}$ in DM patients was obtained from various countries in Africa. Two of the studies involved participants from Nigeria [41, 42], two from Ethiopia [43, 44], two from South Africa [39, 40], one each from Guinea [45], Egypt [21], Kenya [46], Ivory coast [47], Zimbabwe [48], Tanzania [49], and Ghana [17].
Regarding the sampling technique employed, 7 of the studies [17, 21, 41, 42, 46-48] used the consecutive sampling technique to select study participants. However, two studies $[45,49]$ did not report their sampling methods. With respect to the tools used to assess ED in DM patients, 10 studies [21, 41-49] used the International Index of Erectile Function, two $[39,40]$ used the Sexual Health Inventory for Men, and one study [17] used the Golombok Rust Inventory of Sexual Satisfaction. The quality score of each primary study, based on the Newcastle-Ottawa quality score assessment, was moderate to high for all 13 articles assessed (Table 1).

3.3. Prevalence of Erectile Dysfunction. Our meta-analysis using the random-effects model showed that the estimated overall prevalence of ED in patients with DM was $71.45 \%$ (95\% CI: 60.22-82.69) with a significant level of heterogeneity $\left(I^{2}=98.7 \% ; p<0.001\right)$ (Figure 2$)$.

3.4. Subgroup Analysis. To overcome the presence of heterogeneity, subgroup analysis using country, publication year, sample size, and sampling technique was done. Based on this, the prevalence of ED was found to be $84.92 \%$ in Nigeria, $73.33 \%$ in studies published since 2010 , and $74.51 \%$ in studies with a sample size less than 300 (Table 2).

3.5. Meta-Regression Analysis. To identify the sources of heterogeneity, meta-regression analysis was undertaken by considering year of publication, sample size, and sampling technique. However, our results showed that the covariates were not significantly associated with the presence of heterogeneity (Table 3 ).

3.6. Sensitivity Analysis. To evaluate the effect of an individual study on the pooled effect size, sensitivity analysis was conducted. Sensitivity analyses using the random-effects model revealed that no single study influenced the overall prevalence of ED in DM patients (Figure 3).

3.7. Publication Bias. We found that there was no publication bias among the included studies, as depicted by the symmetrical distribution of our funnel plot (Figure 4) and the results from our Egger's regression test $(p=0.226)$.

3.8. BMI. The pooled effects of five studies showed that BMI of $\geq 30 \mathrm{~kg} / \mathrm{m}^{2}$ was not statistically associated with ED in patients with DM (Figure 5). The heterogeneity test $\left(I^{2}=89.5 \%\right)$ showed significant evidence of variation across studies. The evidence from Egger's regression test showed that there was no publication bias $(p=0.807)$.

3.9. Glycosylated Hemoglobin (Hgalc). According to our current meta-analysis, those who had normal glycated hemoglobin were $7 \%$ less likely to develop ED compared with those who had a glycated hemoglobin value $\geq 7 \%$, although 


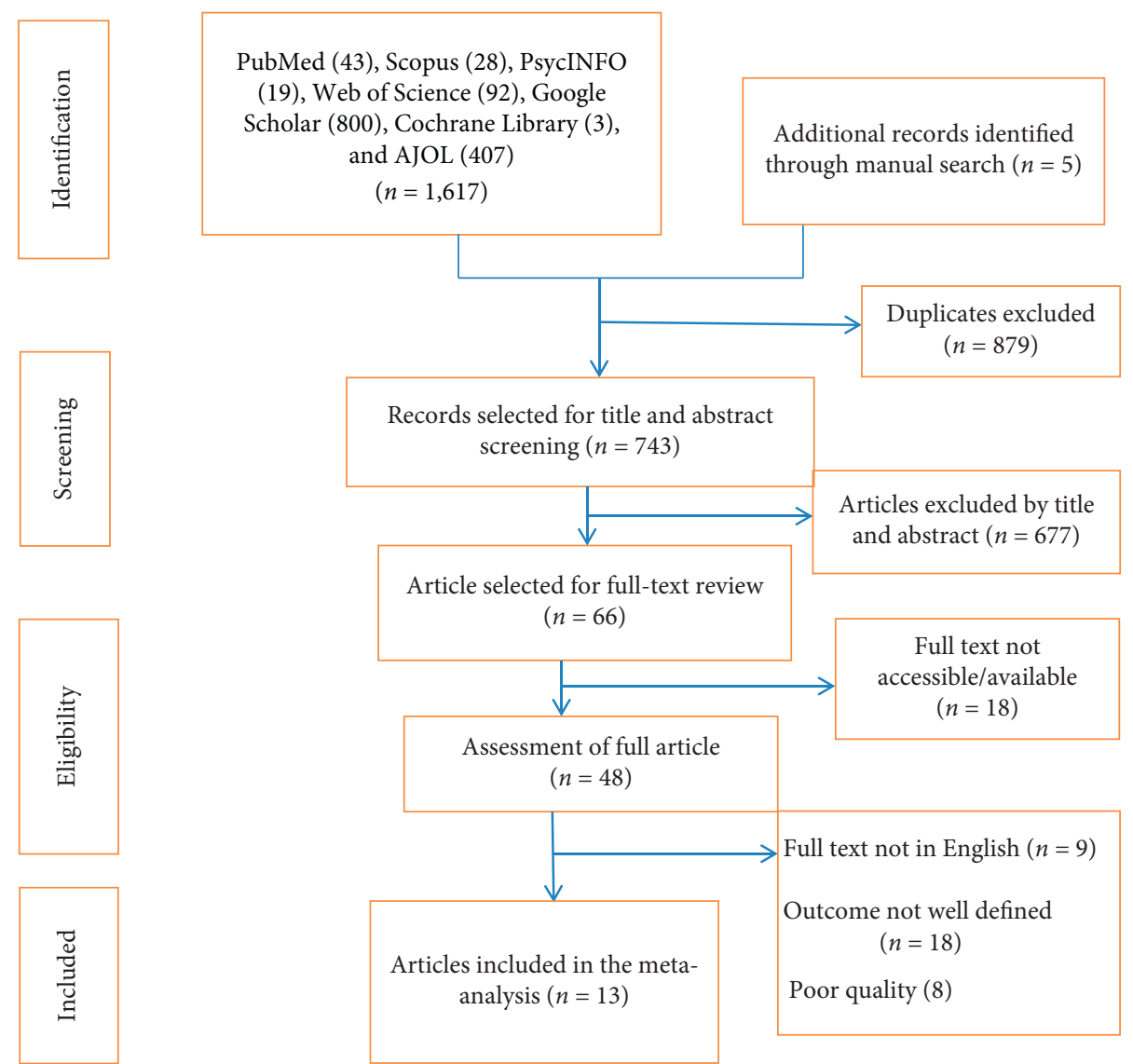

Figure 1: PRISMA flow chart for study selection.

TABLE 1: Baseline characteristics of the included studies.

\begin{tabular}{|c|c|c|c|c|c|c|c|c|c|}
\hline First author & $\begin{array}{l}\text { Publication } \\
\text { year }\end{array}$ & Country & Study design & $\begin{array}{l}\text { Sample } \\
\text { size }\end{array}$ & $\begin{array}{l}\text { Prevalence } \\
\text { of ED ( } 95 \% \\
\text { CI) }\end{array}$ & $\begin{array}{c}\text { Data } \\
\text { collection year }\end{array}$ & Data collection tool & $\begin{array}{l}\text { Sampling } \\
\text { technique }\end{array}$ & $\begin{array}{l}\text { Quality } \\
\text { score } \\
(10)\end{array}$ \\
\hline Baldé et al. [45] & 2006 & Guinea & $\begin{array}{c}\text { Cross- } \\
\text { sectional }\end{array}$ & 187 & $\begin{array}{c}48(40.8 \\
55.2)\end{array}$ & NR & $\begin{array}{l}\text { International Index } \\
\text { of Erectile Function }\end{array}$ & NR & 7 \\
\hline $\begin{array}{l}\text { El Saghier et al. } \\
\text { [21] }\end{array}$ & 2015 & Egypt & $\begin{array}{l}\text { Cross- } \\
\text { sectional }\end{array}$ & 70 & $\begin{array}{l}85.7(77.5 \\
93.9)\end{array}$ & $\begin{array}{l}\text { March } 2014 \text { to } \\
\text { January } 2015\end{array}$ & $\begin{array}{l}\text { International Index } \\
\text { of Erectile Function- } \\
5\end{array}$ & Consecutive & 7 \\
\hline $\begin{array}{l}\text { Kemp and } \\
\text { Rheeder [39] }\end{array}$ & 2015 & $\begin{array}{l}\text { South } \\
\text { Africa }\end{array}$ & $\begin{array}{c}\text { Cross- } \\
\text { sectional }\end{array}$ & 150 & $\begin{array}{c}95(91.5 \\
98.5)\end{array}$ & NR & $\begin{array}{l}\text { The Sexual Health } \\
\text { Inventory for Men }\end{array}$ & $\begin{array}{l}\text { Simple } \\
\text { random }\end{array}$ & 7 \\
\hline $\begin{array}{l}\text { Likata et al. } \\
\text { [46] }\end{array}$ & 2012 & Kenya & $\begin{array}{l}\text { Cross- } \\
\text { sectional }\end{array}$ & 350 & $\begin{array}{c}68.8(63.9 \\
73.6)\end{array}$ & NR & $\begin{array}{l}\text { International Index } \\
\text { of Erectile Function }\end{array}$ & Consecutive & 7 \\
\hline $\begin{array}{l}\text { Lokrou and } \\
\text { Soumahoro } \\
{[47]}\end{array}$ & 2011 & $\begin{array}{l}\text { Ivory } \\
\text { coast }\end{array}$ & $\begin{array}{l}\text { Cross- } \\
\text { sectional }\end{array}$ & 112 & $\begin{array}{l}74.1(65.9 \\
82.2)\end{array}$ & NR & $\begin{array}{l}\text { International Index } \\
\text { of Erectile Function }\end{array}$ & Consecutive & 7 \\
\hline $\begin{array}{l}\text { Mutagaywa } \\
\text { et al. [49] }\end{array}$ & 2014 & Tanzania & $\begin{array}{l}\text { Cross- } \\
\text { sectional }\end{array}$ & 312 & $\begin{array}{l}55.1(49.5 \\
\quad 60.6)\end{array}$ & $\begin{array}{l}\text { May to } \\
\text { December } \\
2011\end{array}$ & $\begin{array}{l}\text { International Index } \\
\text { of Erectile Function }\end{array}$ & NR & 7 \\
\hline $\begin{array}{l}\text { Olarinoye et al. } \\
\text { [41] }\end{array}$ & 2006 & Nigeria & $\begin{array}{c}\text { Cross- } \\
\text { sectional }\end{array}$ & 77 & $\begin{array}{c}74(64.2 \\
83.8)\end{array}$ & NR & $\begin{array}{l}\text { International Index } \\
\text { of Erectile Function }\end{array}$ & Consecutive & 7 \\
\hline $\begin{array}{l}\text { Owiredu et al. } \\
{[17]}\end{array}$ & 2011 & Ghana & $\begin{array}{l}\text { Cross- } \\
\text { sectional }\end{array}$ & 300 & $\begin{array}{l}67.9(62.4 \\
73.3)\end{array}$ & $\begin{array}{c}\text { November } \\
2010 \text { to March } \\
2011\end{array}$ & $\begin{array}{l}\text { Golombok Rust } \\
\text { Inventory of Sexual } \\
\text { SATISFACTION }\end{array}$ & Consecutive & 7 \\
\hline $\begin{array}{l}\text { Pasipanodya } \\
\text { Ian } \\
\text { Machingura } \\
{[48]}\end{array}$ & 2018 & Zimbabwe & $\begin{array}{l}\text { Cross- } \\
\text { sectional }\end{array}$ & 348 & $\begin{array}{l}73.9(69.3 \\
78.5)\end{array}$ & $\begin{array}{c}\text { October 23, } \\
2013 \text { to July } 9 \text {, } \\
2014\end{array}$ & $\begin{array}{l}\text { International Index } \\
\text { of Erectile Function }\end{array}$ & Consecutive & 6 \\
\hline
\end{tabular}


TABLE 1: Continued.

\begin{tabular}{|c|c|c|c|c|c|c|c|c|c|}
\hline First author & $\begin{array}{l}\text { Publication } \\
\text { year }\end{array}$ & Country & Study design & $\begin{array}{l}\text { Sample } \\
\text { size }\end{array}$ & $\begin{array}{c}\text { Prevalence } \\
\text { of ED ( } 95 \% \\
\text { CI) }\end{array}$ & $\begin{array}{c}\text { Data } \\
\text { collection year }\end{array}$ & Data collection tool & $\begin{array}{l}\text { Sampling } \\
\text { technique }\end{array}$ & $\begin{array}{c}\text { Quality } \\
\text { score } \\
(10) \\
\end{array}$ \\
\hline Seid et al. [43] & 2017 & Ethiopia & $\begin{array}{l}\text { Cross- } \\
\text { sectional }\end{array}$ & 249 & $\begin{array}{l}69.9(64.2 \\
75.6)\end{array}$ & $\begin{array}{c}\text { January } \\
\text { 1-February } \\
30,2016\end{array}$ & $\begin{array}{l}\text { International Index } \\
\text { of Erectile Function }\end{array}$ & $\begin{array}{l}\text { Systematic } \\
\text { random }\end{array}$ & 8 \\
\hline $\begin{array}{l}\text { Ugwumba } \\
\text { et al. [42] }\end{array}$ & 2018 & Nigeria & $\begin{array}{l}\text { Cross- } \\
\text { sectional }\end{array}$ & 325 & $\begin{array}{l}94.7(92.2 \\
97.1)\end{array}$ & $\begin{array}{c}\text { September } \\
2016 \text { to } \\
\text { December } \\
2017\end{array}$ & $\begin{array}{l}\text { International Index } \\
\text { of Erectile Function }\end{array}$ & Consecutive & 7 \\
\hline Walle et al. [44] & 2018 & Ethiopia & $\begin{array}{l}\text { Cross- } \\
\text { sectional }\end{array}$ & 422 & $\begin{array}{l}85.5(82.1 \\
88.8)\end{array}$ & $\begin{array}{l}\text { January to } \\
\text { March } 2016\end{array}$ & $\begin{array}{l}\text { International Index } \\
\text { of Erectile Function }\end{array}$ & Systematic & 6 \\
\hline $\begin{array}{l}\text { Webb et al. } \\
{[40]}\end{array}$ & 2014 & $\begin{array}{l}\text { South } \\
\text { Africa }\end{array}$ & $\begin{array}{c}\text { Cluster } \\
\text { randomized } \\
\text { control trial }\end{array}$ & 599 & $\begin{array}{c}36(32.1 \\
39.8)\end{array}$ & NR & $\begin{array}{c}\text { Sexual Health } \\
\text { Inventory For Men }\end{array}$ & Systematic & 8 \\
\hline
\end{tabular}

NR; not reported.

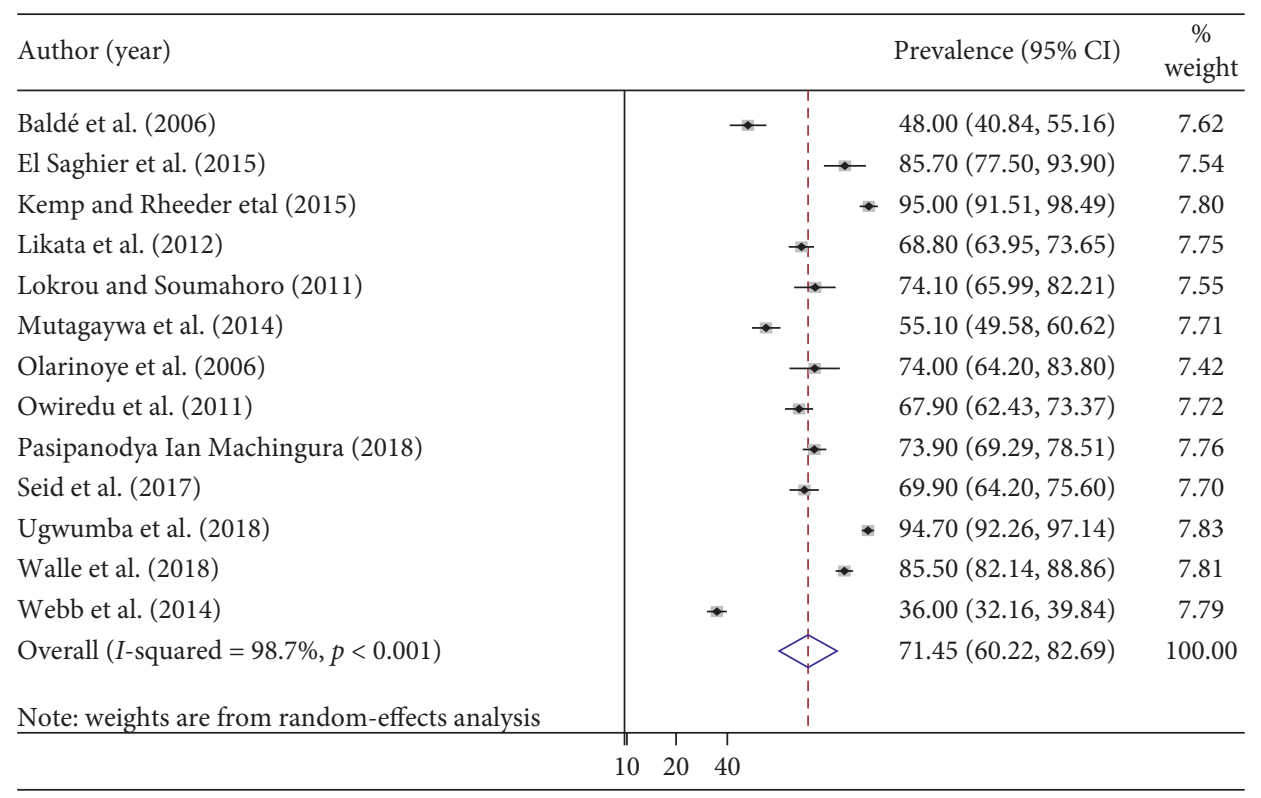

FIGURE 2: Forest plot of the prevalence of erectile dysfunction in patients with diabetes mellitus.

this association was not statistically significant (OR: 0.93; 95\% CI: 0.15-5.91) (Figure 6). The heterogeneity test $\left(I^{2}=94.4 \%\right)$ showed significant evidence of variation across studies. The result of Egger's regression test showed no evidence of publication bias $(p=0.147)$.

\section{Discussion}

The prevalence of ED in this meta-analysis was estimated to be $71.45 \%$ in patients with DM. This indicates that ED is highly prevalent in diabetic patients and is an inadequately controlled complication of DM in African populations. Hence, a serious and multifactorial approach is required to manage diabetes-related ED, with emphasis being placed on treatment adherence, self-care, and health information dissemination.

Our estimated prevalence of ED in DM patients in Africa is substantially higher than that reported in a systematic review and meta-analysis conducted at the global level, which sets the prevalence at 52.5\% [50]. This variation could be justified by the different diagnostic criteria for ED, differences in methodology, and population characteristics.

The subgroup analysis in this study showed that the pooled prevalence of ED among diabetic patients in Nigeria was $84.92 \%$ (95\% CI: 64.66-105.17), which was the highest among the African nations examined, including the prevalence in Ethiopia (77.88\%; 95\% CI: 62.59-93.16) and South Africa (65.5\%; 95\% CI: 7.9-123.3). This variation might be due to differences in health-seeking behavior between the populations, differences in the diagnostic methods, and sociodemographic characteristics.

Though we identified two factors (BMI and glycated hemoglobin) that may be related to ED in DM patients, a BMI of $\geq 30 \mathrm{~kg} / \mathrm{m}^{2}$ and glycated hemoglobin of $\geq 7 \%$ were not significantly associated with ED among diabetic patients. Specifically, we found that those who had BMI of $\geq 30 \mathrm{~kg} / \mathrm{m}^{2}$ were $26 \%$ more likely to develop ED, although the increase 
TABLE 2: The prevalence of erectile dysfunction and estimates of heterogeneity when publications are divided into different subgroups.

\begin{tabular}{|c|c|c|c|c|c|c|}
\hline Sub-group & Category & No. of studies included & Sample size & Prevalence $(95 \% \mathrm{CI})$ & $p$ value & $I^{2}$ \\
\hline \multirow{2}{*}{ By year of publication } & Before 2010 & 2 & 264 & $60.78(35.3,86.25)$ & $<0.001$ & 94.3 \\
\hline & 2010 and above & 11 & 3,237 & $73.33(61.23,85.44)$ & $<0.001$ & 98.8 \\
\hline \multirow{2}{*}{ Sample size } & $<300$ & 6 & 845 & $74.51(59.54,89.5)$ & $<0.001$ & 97 \\
\hline & $\geq 300$ & 7 & 2,656 & $68.88(52.17,85.58)$ & $<0.001$ & 99.2 \\
\hline \multirow{4}{*}{ Country } & Nigeria & 2 & 402 & $84.92(64.66,105.17)$ & $<0.001$ & 93.8 \\
\hline & South Africa & 2 & 749 & $65.51(7.9,123.32)$ & $<0.001$ & 99.8 \\
\hline & Ethiopia & 2 & 671 & $77.88(62.59,93.16)$ & $<0.001$ & 95.3 \\
\hline & Others & 7 & 1,679 & $67.52(59.45,75.59)$ & $<0.001$ & 92.2 \\
\hline \multirow{4}{*}{ Sampling technique } & Systematic & 3 & 996 & $83.63(71.6,95.66)$ & $<0.001$ & 97.1 \\
\hline & Simple random & 1 & 70 & $85.7(77.5,93.9)$ & 0.1 & 0.1 \\
\hline & Consecutive & 7 & 2,136 & $67.22(50.2,84.24)$ & $<0.001$ & 98.5 \\
\hline & Not specified & 2 & 299 & $60.98(35.40,86.55)$ & $<0.001$ & 95.5 \\
\hline
\end{tabular}

TABLE 3: Meta-regression analysis for the included studies to identify the sources of heterogeneity.

\begin{tabular}{lcccccc}
\hline Variables & Category & Coef. & Std. err. & $t$ & $p<|t|$ & $(95 \%$ conf. interval) \\
\hline By year of publication & $\begin{array}{c}\text { Before } 2010 \text { (reference) } \\
2010 \text { and above }\end{array}$ & 0.421 & 1.106 & 0.38 & 0.771 & $(-2.043$ to 2.88) \\
\hline Sample size & $\begin{array}{c}<300 \text { (reference) } \\
\geq 300\end{array}$ & -0.041 & 0.487 & -0.08 & 0.934 & $(-1.126$ to 1.044$)$ \\
\hline & $\quad$ Systematic & 0.614 & 1.267 & 0.51 & 0.628 & $(-2.35$ to 3.63$)$ \\
Sampling technique & Simple random & 0.254 & 1.85 & 0.14 & 0.895 & $(-4.13$ to 4.64$)$ \\
& $\quad \begin{array}{c}\text { Consecutive } \\
\text { Not specified (reference) }\end{array}$ & 0.202 & 1.219 & 0.17 & 0.873 & $(-2.68$ to 3.08$)$
\end{tabular}

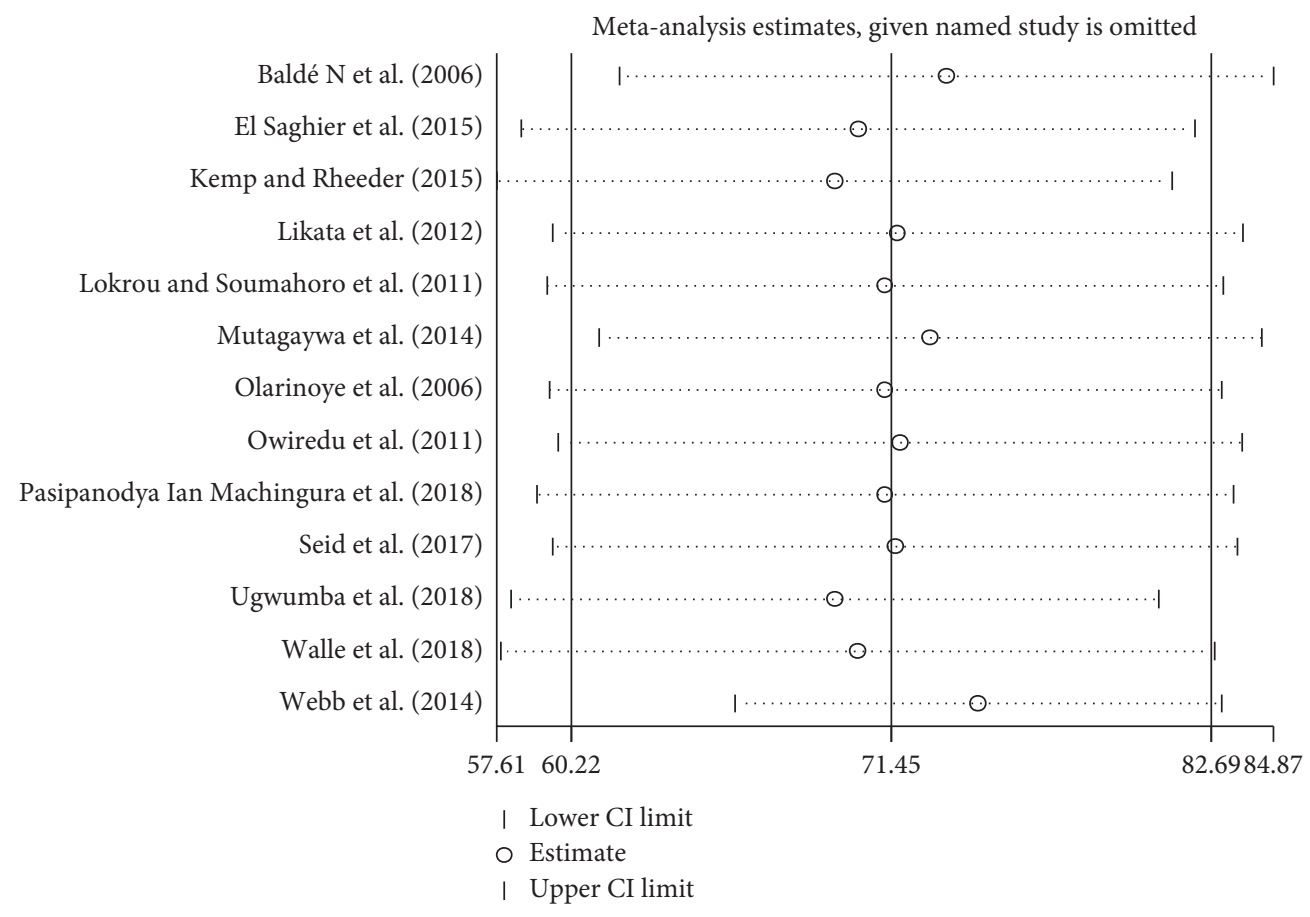

FIgURE 3: Sensitivity analysis of the 13 studies.

was not statistically significant. This is supported by studies conducted on populations in Vietnam [51] and Brazil [52]. Similarly, we found that those who had glycosylated hemoglobin of $<7 \%$ were $7 \%$ less likely to develop ED, although the decrease was not statistically significant. This too was supported by studies done on Korean [12] and Chinese [53] populations.

This study has clinical implications in that the high prevalence of ED in DM patients should guide health care professionals to increase patient awareness of DM 


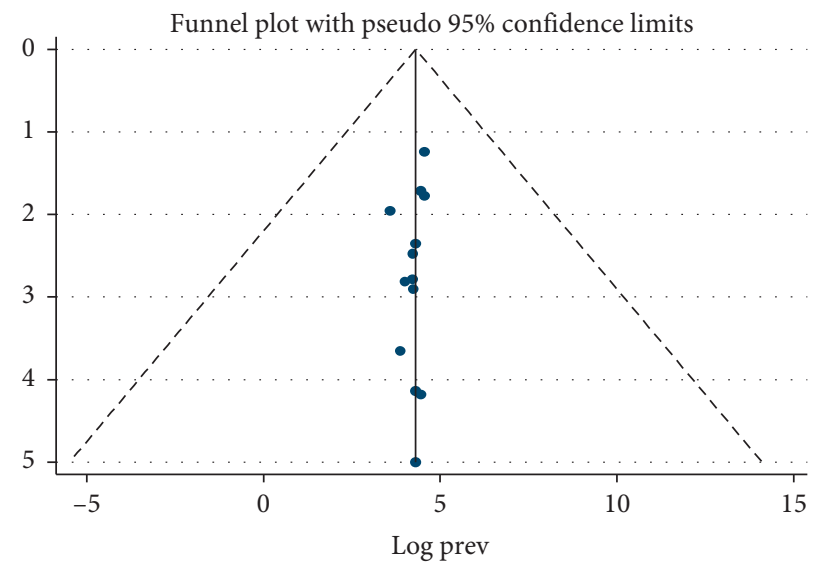

Figure 4: Funnel plot for the presence of publication bias among the 13 included studies.

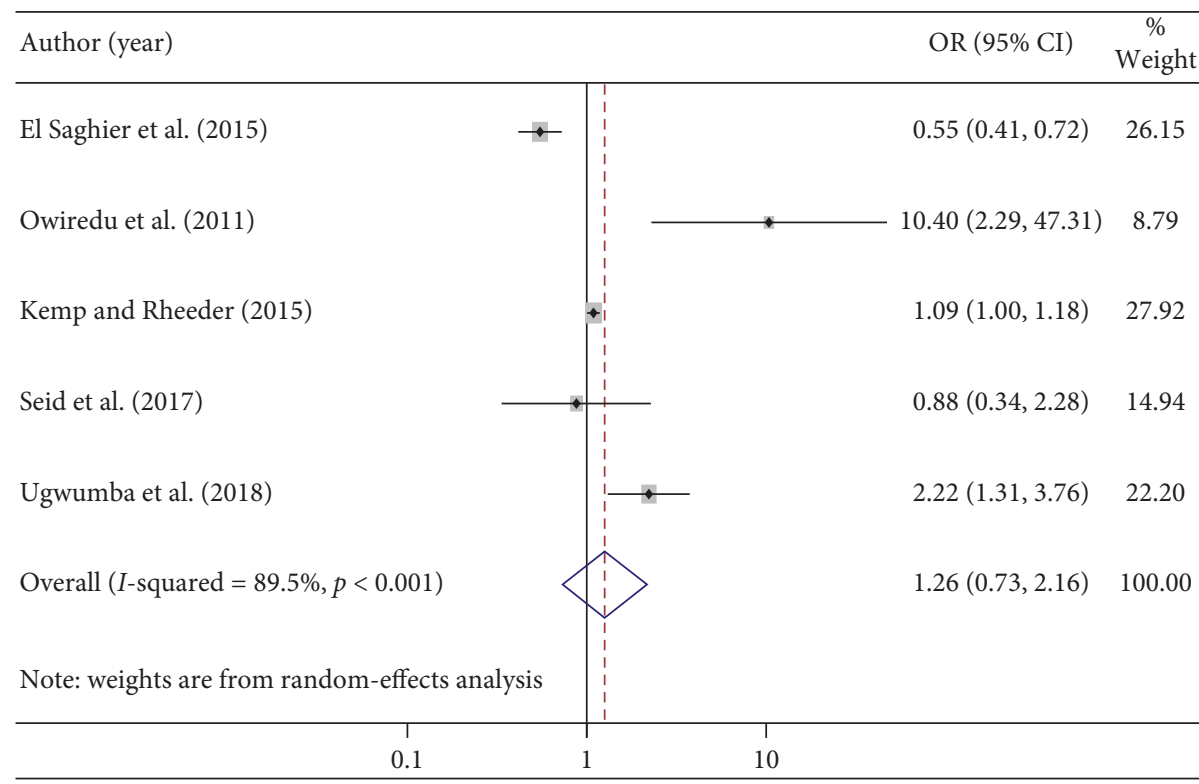

FIGURE 5: The pooled effects of body mass index on erectile dysfunction.

\begin{tabular}{|c|c|c|c|}
\hline Author (year) & & OR $(95 \% \mathrm{CI})$ & $\begin{array}{c}\% \\
\text { weight } \\
\end{array}$ \\
\hline El Saghier et al. (2015) & & $0.02(0.00,0.11)$ & 22.34 \\
\hline Owiredu et al. (2011) & & $1.00(0.39,2.55)$ & 25.58 \\
\hline Pasipanodya Ian Machingura et al. (2018) & - & $3.65(1.19,11.23)$ & 24.86 \\
\hline Ugwumba et al. (2018) & $\rightarrow$ & $5.92(4.46,7.86)$ & 27.21 \\
\hline Overall $(I$-squared $=94.4 \%, p<0.001)$ & & $0.93(0.15,5.91)$ & 100.00 \\
\hline \multicolumn{4}{|l|}{ Note: weights are from random-effects analysis } \\
\hline 0.1 & $\begin{array}{c}1 \\
10\end{array}$ & & \\
\hline
\end{tabular}

Figure 6: The pooled effects of glycated hemoglobin $\geq 7 \%$ on erectile dysfunction. 
complications and design preventive measures and treatments to improve patient quality of life. In addition, identifying associated factors may help health care professionals treat DM patients with ED during their clinical care.

The meta-analysis conducted in this study has several limitations that should be considered in future research. First, it is difficult to determine if the results from various countries is representative of the entire content because no data were found for all of Africa. Second, only English articles were considered, and thus, we could be missing important data published in other languages. Moreover, as mentioned previously, we did not identify all of the potential predictors of ED among patients with DM. Therefore, further study is needed to identify associated factors for the development of ED among patients with DM may be necessary, such as age, duration of diabetes, preexisting illness, sedentary lifestyle, and smoking.

\section{Conclusion and Recommendations}

This study revealed that the prevalence of ED remains high in DM patients in Africa. That said, the prevalence of ED differed by country. Therefore, situation-based interventions and country context-specific preventive strategies should be developed to reduce the prevalence of ED among patients with DM.

\section{Abbreviations}

AOR: $\quad$ Adjusted odds ratio

CI: $\quad$ Confidence interval

DM: $\quad$ Diabetes mellitus

ED: $\quad$ Erectile dysfunction

IDF: International Diabetic Federation

PRISMA: Preferred Reporting Items for Systematic

Reviews and Meta-Analyses.

\section{Conflicts of Interest}

The authors declare that they have no competing interests.

\section{Authors' Contributions}

WSS and TYA developed the protocol and were involved in the design, the selection of the studies, data extraction, statistical analysis, and the development of the initial drafts of the manuscript. YAA and TYA were involved in data extraction, quality assessment, statistical analysis, and revising the manuscript. WSS and YAA prepared the final draft of the manuscript. All authors read and approved the final draft of the manuscript.

\section{Supplementary Materials}

Supplementary file 1: methodological quality assessment of cross-sectional studies using modified Newcastle-Ottawa Scale (NOS). (Supplementary Materials)

\section{References}

[1] G. Roglic, "WHO Global report on diabetes: a summary," International Journal of Noncommunicable Diseases, vol. 1, no. 1, p. 3, 2016.

[2] IDF, Diabetes Atlas, IDF, Brussels, Belgium, 8th edition, 2017.

[3] J.-C. Mbanya and E. Sobngwi, "Diabetes microvascular and macrovascular disease in Africa," Journal of Cardiovascular Risk, vol. 10, no. 2, pp. 97-102, 2003.

[4] A. M. Ibrahim, "Erectile dysfunction in diabetes: an overview," International Journal of Innovative Studies in Medical Sciences, vol. 3, no. 1, pp. 13-14, 2019.

[5] I. A. Ayta, J. B. McKinlay, and R. J. Krane, "The likely worldwide increase in erectile dysfunction between 1995 and 2025 and some possible policy consequences," BJU International, vol. 84, no. 1, pp. 50-56, 1999.

[6] N. Consensus, "Development panel on impotence. NIH consensus conference," JAMA, vol. 270, pp. 83-90, 1993.

[7] T. F. Lue, "Erectile dysfunction," New England Journal of Medicine, vol. 342, no. 24, pp. 1802-1813, 2000.

[8] J. P. Heaton and M. A. Adams, "Causes of erectile dysfunction," Endocrine, vol. 23, no. 2-3, pp. 119-123, 2004.

[9] I. S. de Tejada, I. Goldstein, K. Azadzoi, R. J. Krane, and R. A. Cohen, "Impaired neurogenic and endothelium-mediated relaxation of penile smooth muscle from diabetic men with impotence," New England Journal of Medicine, vol. 320, no. 16 , pp. 1025-1030, 1989.

[10] R. C. Kolodny, C. B. Kahn, H. H. Goldstein, and D. M. Barnett, "Sexual dysfunction in diabetic men," Diabetes, vol. 23, no. 4, pp. 306-309, 1974.

[11] D. Fedele, C. Coscelli, F. Santeusanio et al., "Erectile dysfunction in diabetic subjects in Italy. Gruppo italiano studio deficit erettile nei diabetici," Diabetes Care, vol. 21, no. 11, pp. 1973-1977, 1998.

[12] N. H. Cho, C. W. Ahn, J. Y. Park et al., "Prevalence of erectile dysfunction in Korean men with Type 2 diabetes mellitus," Diabetic Medicine, vol. 23, no. 2, pp. 198-203, 2006.

[13] A. I. El-Sakka and K. A. Tayeb, "Erectile dysfunction risk factors in noninsulin dependent diabetic Saudi patients," Journal of Urology, vol. 169, no. 3, pp. 1043-1047, 2003.

[14] A. Al-Hunayan, M. Al-Mutar, E. O. Kehinde, L. Thalib, and M. Al-Ghorory, "The prevalence and predictors of erectile dysfunction in men with newly diagnosed with type 2 diabetes mellitus," BJU International, vol. 99, no. 1, pp. 130-134, 2007.

[15] A. Dan, K. Chakraborty, M. Mondal, R. Neogi, S. Chatterjee, and M. Makhal, "Erectile dysfunction in patients with diabetes mellitus: its magnitude, predictors and their bio-psycho-social interaction: a study from a developing country," Asian Journal of Psychiatry, vol. 7, pp. 58-65, 2014.

[16] H. De Klerk, P. De Villiers, and S. Isaacs, "Prevalence and characteristics of erectile dysfunction in black and mixed race primary care populations of the Cape Flats and Helderberg Basin area of the Western Cape, South Africa," South African Family Practice, vol. 45, no. 1, pp. 14-20, 2003.

[17] W. K. Owiredu, N. Amidu, H. Alidu, C. Sarpong, and C. K. Gyasi-Sarpong, "Determinants of sexual dysfunction among clinically diagnosed diabetic patients," Reproductive Biology and Endocrinology, vol. 9, no. 1, p. 70, 2011.

[18] S. Berrada, N. Kadri, S. Mechakra-Tahiri, and C. Nejjari, "Prevalence of erectile dysfunction and its correlates: a population-based study in Morocco," International Journal of Impotence Research, vol. 15, no. S1, pp. S3-S7, 2003.

[19] R. Seyam, A. Albakry, A. Ghobish, H. Arif, K. Dandash, and H. Rashwan, "Prevalence of erectile dysfunction and its 
correlates in Egypt: a community-based study," International Journal of Impotence Research, vol. 15, no. 4, pp. 237-245, 2003.

[20] A. Bortolotti, D. Fedele, L. Chatenoud et al., "Cigarette smoking: a risk factor for erectile dysfunction in diabetics," European Urology, vol. 40, no. 4, pp. 392-397, 2001.

[21] E. O. A. El Saghier, S. E. Shebl, O. A. Fawzy, l. M. Eltayeb, L. M. A. Bekhet, and A. Gharib, "Androgen deficiency and erectile dysfunction in patients with type 2 diabetes," Clinical Medicine Insights: Endocrinology and Diabetes, vol. 8, p. S27700, 2015.

[22] C. G. Bacon, F. B. Hu, E. Giovannucci, D. B. Glasser, M. A. Mittleman, and E. B. Rimm, "Association of type and duration of diabetes with erectile dysfunction in a large cohort of men," Diabetes Care, vol. 25, no. 8, pp. 1458-1463, 2002.

[23] H. Besiroglu, A. Otunctemur, and E. Ozbek, "The relationship between metabolic syndrome, its components, and erectile dysfunction: a systematic review and a meta-analysis of observational studies," The Journal of Sexual Medicine, vol. 12, no. 6, pp. 1309-1318, 2015.

[24] J. Buvat, M. Maggi, L. Gooren et al., "Endocrine aspects of male sexual dysfunctions," The Journal of Sexual Medicine, vol. 7, no. 4, pp. 1627-1656, 2010.

[25] S. Kassier and F. Veldman, "When science meets culture: the prevention and management of erectile dysfunction in the 21st century," South African Journal of Clinical Nutrition, vol. 27, no. 1, pp. 7-12, 2014.

[26] L. S. Malavige and J. C. Levy, "Erectile dysfunction in diabetes mellitus," The Journal of Sexual Medicine, vol. 6, no. 5, pp. 1232-1247, 2009.

[27] G. De Berardis, F. Pellegrini, M. Franciosi et al., "Longitudinal assessment of quality of life in patients with type 2 diabetes and self-reported erectile dysfunction," Diabetes Care, vol. 28, no. 11, pp. 2637-2643, 2005.

[28] P. L. Chye, "Traditional Asian folklore medicines in sexual health," Indian Journal of Urology, vol. 22, no. 3, p. 241, 2006.

[29] S. Cooper, N. Leon, H. Namadingo, K. Bobrow, and A. J. Farmer, “"My wife's mistrust. That's the saddest part of being a diabetic": a qualitative study of sexual well-being in men with Type 2 diabetes in sub-Saharan Africa," PLoS One, vol. 13, no. 9, Article ID e0202413, 2018.

[30] K. T. McVary, S. Carrier, H. Wessells, The Subcommittee on Smoking and Erectile Dysfunction Socioeconomic Committee, and Sexual Medicine Society of North America, "Smoking and erectile dysfunction: evidence based analysis," Journal of Urology, vol. 166, no. 5, pp. 1624-1632, 2001.

[31] K. Esposito, F. Giugliano, C. Di Palo et al., "Effect of lifestyle changes on erectile dysfunction in obese men," JAMA, vol. 291, no. 24, pp. 2978-2984, 2004.

[32] P. A. Modesti, G. Reboldi, F. P. Cappuccio et al., "Panethnic differences in blood pressure in Europe: a systematic review and meta-analysis," PLoS One, vol. 11, no. 1, Article ID e0147601, 2016.

[33] K. G. Yazew, T. A. Walle, and A. W. Azagew, "Prevalence of anti-diabetic medication adherence and determinant factors in Ethiopia: a systemic review and meta-analysis, 2019," International Journal of Africa Nursing Sciences, vol. 11, p. 100167, 2019.

[34] R. DerSimonian and N. Laird, "Meta-analysis in clinical trials," Controlled Clinical Trials, vol. 7, no. 3, pp. 177-188, 1986.

[35] T. B. Huedo-Medina, J. Sánchez-Meca, F. Marín-Martínez, and J. Botella, "Assessing heterogeneity in meta-analysis: Q statistic or $I^{2}$ index?"Psychological Methods, vol. 11, no. 2, pp. 193-206, 2006.

[36] M. Egger, G. Davey-Smith, and D. Altman, Systematic Reviews in Health Care: Meta-Analysis in Context, John Wiley \& Sons, Hoboken, NJ, USA, 2008.

[37] StataCorp LLC, Stata Statistical Software (Version Release 14), StataCorp LLC, College Station, TX, USA, 2015.

[38] A. Liberati, D. G. Altman, J. Tetzlaff et al., "The PRISMA statement for reporting systematic reviews and meta-analyses of studies that evaluate health care interventions: explanation and elaboration," PLoS Medicine, vol. 6, no. 7, Article ID e1000100, 2009.

[39] T. Kemp and P. Rheeder, "The prevalence and associations of erectile dysfunction in a South African male diabetic urban population," Journal of Endocrinology, Metabolism and Diabetes of South Africa, vol. 20, no. 3, pp. 134-139, 2015.

[40] E. M. Webb, P. Rheeder, and D. G. Van Zyl, "Diabetes care and complications in primary care in the Tshwane district of South Africa," Primary Care Diabetes, vol. 9, no. 2, pp. 147154, 2015.

[41] J. Olarinoye, S. Kuranga, I. Katibi, O. Adediran, A. Jimoh, and E. Sanya, "Prevalence and determinants of erectile dysfunction among people with type 2 diabetes in Ilorin, Nigeria," The Nigerian Postgraduate Medical Journal, vol. 13, no. 4, pp. 291-296, 2006.

[42] F. Ugwumba, C. Okafor, I. Nnabugwu II et al., "Prevalence of, and risk factors for erectile dysfunction in male type 2 diabetic outpatient attendees in Enugu, South East Nigeria," Annals of African Medicine, vol. 17, no. 4, p. 215, 2018.

[43] A. Seid, H. Gerensea, S. Tarko, Y. Zenebe, and R. Mezemir, "Prevalence and determinants of erectile dysfunction among diabetic patients attending in hospitals of central and northwestern zone of Tigray, northern Ethiopia: a crosssectional study," BMC Endocrine Disorders, vol. 17, no. 1, p. 16, 2017.

[44] B. Walle, K. R. Lebeta, Y. D. Fita, and H. G. Abdissa, "Prevalence of erectile dysfunction and associated factors among diabetic men attending the diabetic clinic at Felege Hiwot Referral Hospital, Bahir Dar, North West Ethiopia, 2016," BMC Research Notes, vol. 11, no. 1, p. 130, 2018.

[45] N. M. Baldé, A. B. Diallo, M. C. Baldé et al., "Dysfonction érectile et diabète à Conakry (Guinée): fréquence et profil clinique à partir de 187 observations," Annales D'endocrinologie, vol. 67, no. 4, pp. 338-342, 2006.

[46] G. M. U. Likata, M. W. Kuria, Y. Olando, and F. R. Owiti, "Sexual dysfunction among patients with diabetes mellitus," Greener Journal of Medical Sciences, vol. 2, no. 6, pp. 138-145, 2012.

[47] A. Lokrou and S. I. Soumahoro, "La dysfonction érectile chez les personnes atteintes de diabète en Côte-d'Ivoire," Médecine des Maladies Métaboliques, vol. 5, no. 2, pp. 203-207, 2011.

[48] V. C. Pasipanodya Ian Machingura, "Erectile dysfunction among diabetic patients at parirenyatwa group of hospitals in Zimbabwe," Texila International Journal of Public Health, vol. 6, no. 2, pp. 69-73, 2018.

[49] R. K. Mutagaywa, J. Lutale, M. Aboud, and B. A. Kamala, "Prevalence of erectile dysfunction and associated factors among diabetic men attending diabetic clinic at Muhimbili National Hospital in Dar-es-Salaam, Tanzania," Pan African Medical Journal, vol. 17, p. 227, 2014.

[50] Y. Kouidrat, D. Pizzol, T. Cosco et al., "High prevalence of erectile dysfunction in diabetes: a systematic review and metaanalysis of 145 studies," Diabetic Medicine, vol. 34, no. 9, pp. 1185-1192, 2017. 
[51] K. T. Vo, H. Q. Huynh, Q. Huynh et al., "Prevalence of erectile dysfunction and its associated factors among Vietnamese men with type 2 diabetes," Journal of the ASEAN Federation of Endocrine Societies, vol. 29, no. 1, pp. 19-23, 2014.

[52] E. D. Moreira Júnior, W. J. Bestane, E. B. Bartolo, and J. A. S. Fittipaldi, "Prevalence and determinants of erectile dysfunction in Santos, Southeastern Brazil," Sao Paulo Medical Journal, vol. 120, no. 2, pp. 49-54, 2002.

[53] G. Yang, C. Pan, and J. Lu, "Prevalence of erectile dysfunction among Chinese men with type 2 diabetes mellitus," International Journal of Impotence Research, vol. 22, no. 5, pp. 310-317, 2010. 


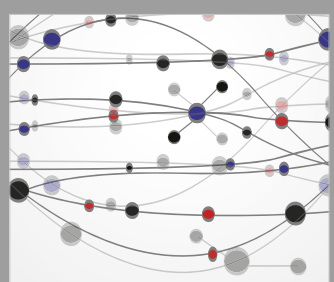

The Scientific World Journal
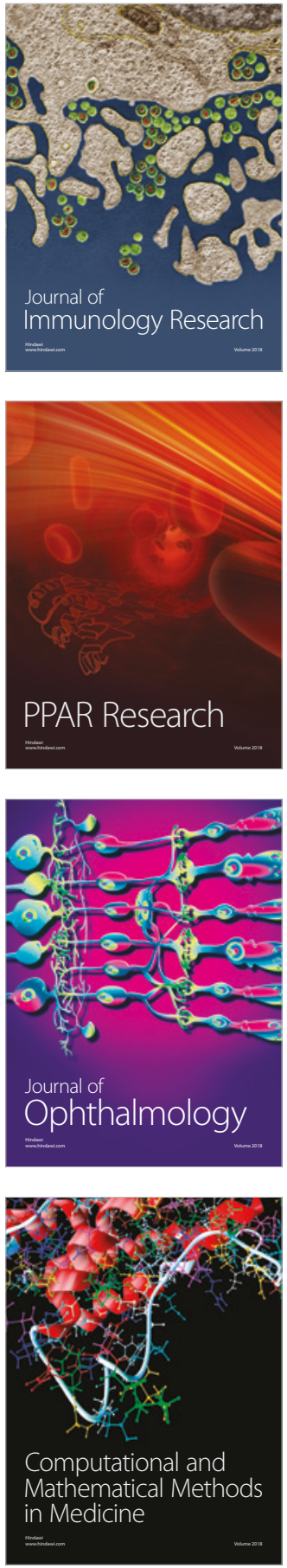

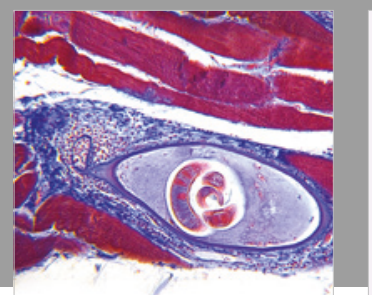

Gastroenterology Research and Practice

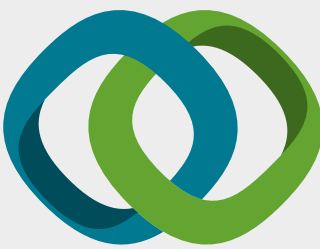

\section{Hindawi}

Submit your manuscripts at

www.hindawi.com
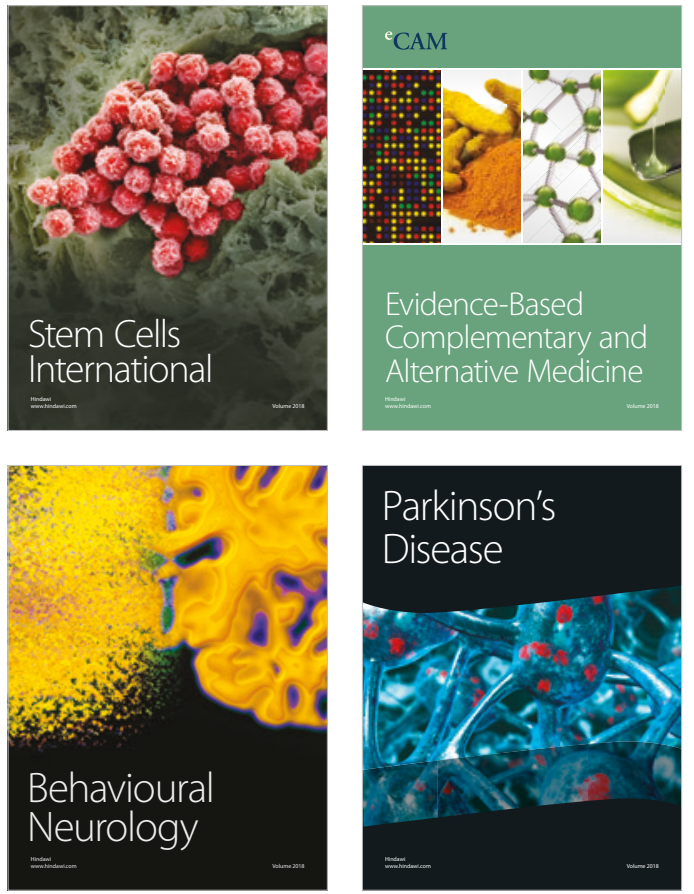

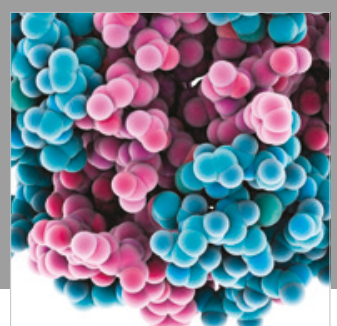

ournal of

Diabetes Research

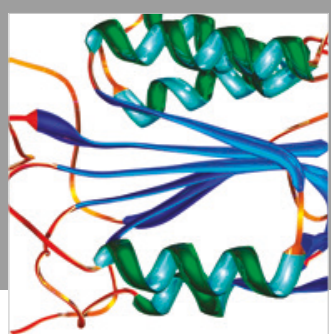

Disease Markers
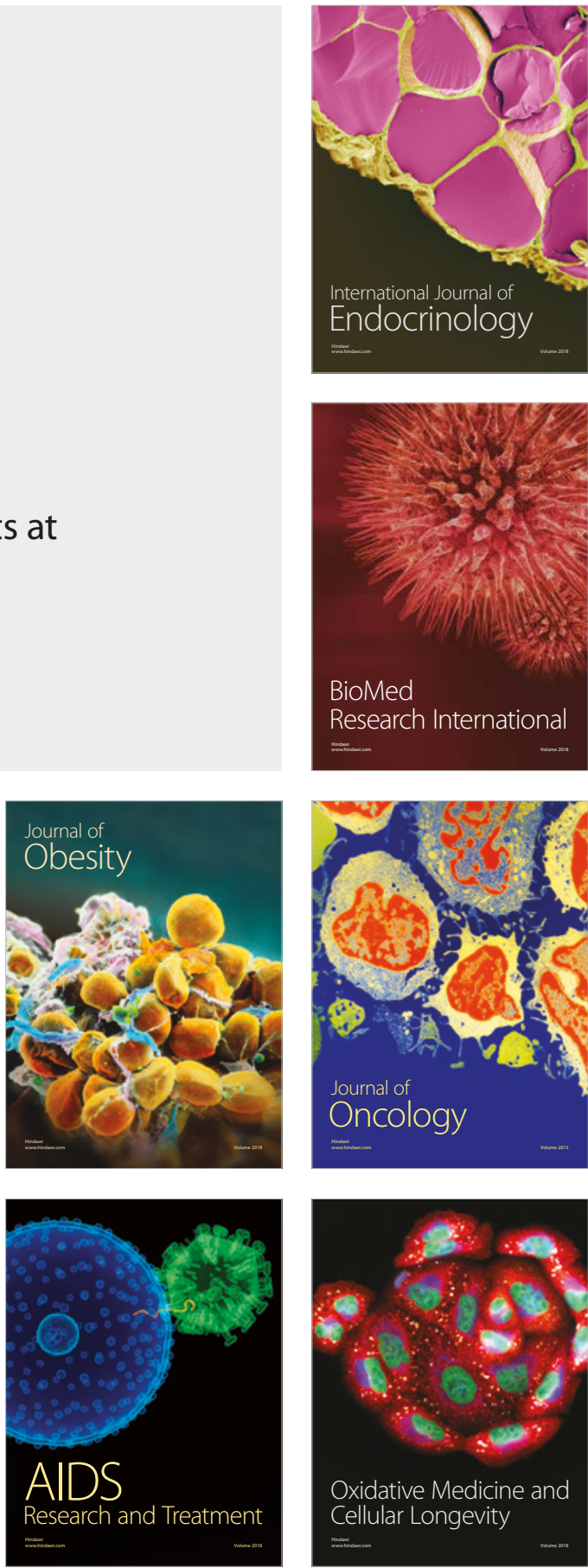